\title{
EFEITO DE FUNGICIDAS PARA CONTROLE DA FERRUGEM ASIÁTICA NA QUALIDADE DE SEMENTES DE SOJA ${ }^{1}$
}

\author{
BRUNA GAGLIARDI², TEREZA CRISTINA DE CARVALHO³, TÚLIO LOURENÇO PUPIM², \\ FRANCISCO GUILHIEN GOMES JUNIOR ${ }^{4}$, TATHIANA SILVA TIMÓTEO ${ }^{5}$, NILCE NAOMI KOBORI ${ }^{5}$, \\ MARIA HELOISA DUARTE MORAES ${ }^{6}$, JOSÉ OTÁVIO MACHADO MENTEN ${ }^{7}$
}

\begin{abstract}
RESUMO - Para avaliar o efeito residual de fungicidas para o controle da ferrugem asiática (Phakopsora pachyrhizi) em sementes de soja do cultivar BRS-133 utilizaram-se 13 tratamentos (Testemunha, Priori + Nimbus, Aproach + Nimbus, Priori Xtra + Nimbus, Sphere + Aureo, Opera, Stratego + Aureo, Nativo + Aureo, Impact Duo + Oppa, Celeiro + Iharol, Battle + Oppa, Aproach Prima + Nimbus, Folicur ). O experimento foi conduzido em campo experimental em Paulínia-SP, em delineamento em blocos ao acaso, com quatro repetições. $\mathrm{O}$ efeito residual dos fungicidas nas sementes foi analisado pelos testes de germinação, envelhecimento acelerado, germinação em areia e pelo teste de sanidade das sementes. Conclui-se que os tratamentos não influenciaram na qualidade das sementes e que o tratamento Battle + Oppa foi eficiente no controle do patógeno Cercospora kikuchii nas sementes.
\end{abstract}

Termos para indexação: Glycine max, Phakopsora pachyrhizi, sanidade, Cercospora kikuchii e tratamento químico.

\section{EFFECT OF FUNGICIDES TO CONTROL ASIAN RUST IN SOYBEAN SEEDS QUALITY}

\begin{abstract}
The residual effect was assessed of fungicides to control Asian rust (Phakopsora pachyrhizi) in soybean seeds of the BRS-133 cultivar using 13 treatments (without fungicide, Priori + Nimbus, Aproach + Nimbus, Priori Xtra + Nimbus, Sphere + Aureo, Opera, Stratego + Aureo, Nativo + Aureo, Impact Duo + Oppa, Celeiro + Iharol, Battle + Oppa, Aproach Prima + Nimbus, Folicur ). The residual effect of the fungicides was analyzed by the germination test, accelerated aging, germination in sand and the seed health test. The treatments did not change the quality of the seeds and the treatment Battle + Oppa was efficient to control the pathogen Cercospora kikuchii on the seeds.
\end{abstract}

Index terms: Glycine max, Phakopsora pachyrhizi, sanity, Cercospora kikuchii and chemist treatment.

${ }^{1}$ Submetido em 17/10/2008. Aceito para publicação em 30/06/2009.

${ }^{2}$ Mestrando (a) em Fitotecnia- Departamento de Produção Vegetal, USP/ ESALQ, brugagliardi@gmail.com.

${ }^{3}$ Mestrando (a) em Fitotecnia- Departamento de Produção Vegetal, USP/ ESALQ; bolsista FAPESP.

${ }^{4}$ Doutorando em Fitotecnia - Departamento de Produção Vegetal, USP/ ESALQ; bolsista FAPESP.
${ }^{5}$ Doutoranda em Fitotecnia - Departamento de Produção Vegetal, USP/ ESALQ; bolsista do CNPq.

${ }^{6}$ Eng. Agr., Dr., Departamento Entomologia, Fitopatologia e Zoologia Agrícola, USP/ESALQ.

${ }^{7}$ Eng. Agr., Dr., Professor Associado do Departamento Entomologia, Fitopatologia e Zoologia Agrícola, USP/ESALQ, Caixa Postal 9, 13418900. Piracicaba, SP. 


\section{INTRODUÇÃO}

O Brasil é um dos maiores produtores de soja do mundo, com uma estimativa de produção de 60 milhões de toneladas na safra 2008/09 (Conab, 2009); porém, a sua produtividade está diminuindo em função da ferrugem asiática, doença causada pelo fungo Phakopsora pachyrhizi, pois possui alto potencial de dano à cultura causando rápido amarelecimento e queda prematura das folhas (Soares et al., 2004).

A primeira constatação do patógeno no Brasil ocorreu na safra 2001/02 (Yorinori et al., 2002), e rapidamente espalhou-se pelas principais regiões produtoras, devido a sua eficiente disseminação pelo vento. O principal dano ocasionado por essa doença é a desfolha precoce, que impede a completa formação das sementes, com conseqüente redução da produtividade (Soares et al., 2004; Embrapa, 2007).

A disponibilidade limitada de cultivares resistentes faz com que o manejo da cultura, por meio de aplicação de agroquímicos, seja uma das alternativas mais usadas (Yorinori, 2002; Godoy e Canteri, 2004; Embrapa, 2009) , devendo este ser realizado de forma racional para não inviabilizar a cultura (Godoy e Canteri, 2004). Outra opção que tem mostrado resultados promissores no controle de patógenos são os óleos essenciais de plantas medicinais (Guiraldo et al., 2004). Segundo o centro de pesquisa em soja (Embrapa, 2009), os efeitos da ferrugem asiática podem ser minimizados com a utilização de cultivares precoces e a redução da área de soja.

O controle da ferrugem da soja compreende diversas medidas em conjunto. Quando a doença já está ocorrendo, o controle químico com fungicidas é, até o momento, o principal método de controle (Godoy e Canteri, 2004).

Os fungicidas são compostos químicos que possuem ação protetora, curativo e sistêmico (Juliatti, 2007). Segundo Sinclair e Hartman (citado por Godoy e Canteri, 2004) estudos mostram que, em condições severas de epidemia, são necessárias de três a cinco aplicações em intervalos de dez dias, o que poderia provocar um efeito residual desses produtos na planta, inclusive nas sementes.

Atualmente, há recomendação oficial de fungicidas para controle das doenças fúngicas da parte aérea (oídio e ferrugem); porém, faltam informações sobre o período residual dos produtos com relação às doenças de final de ciclo (Klingelfuss e Yorinori, 2001). A ferrugem asiática é uma doença que está presente no campo durante praticamente todo o ciclo da planta, pois se trata de uma doença policíclica (vários ciclos do fungo em um único ciclo do hospedeiro) (Godoy et al, 2007); portanto, o efeito residual dos fungicidas pode ser fitotóxico às plantas e permitir que resíduos permaneçam nas suas sementes.

Quanto ao efeito residual destes fungicidas nas sementes, a literatura que aborda este tema é escassa, podendo ser citado um trabalho realizado por Vieira et al. (2001), onde os autores avaliaram a eficiência de quatro fungicidas (fluazinam, benomyl, iprodione e procimidone) no controle de Sclerotinia sclerotiorum em plantas de feijão, sendo que os tratamentos não influenciaram na incidência do patógeno nas sementes.

Em geral, as sementes não manifestam sintomas. No caso da ferrugem asiática, pouco conhecimento se tem sobre a alteração na qualidade (fisiológica e sanitária) das sementes, oriundas de plantas que receberam tratamento para controle da doença.

Desta forma, o objetivo do trabalho foi avaliar possíveis alterações nos parâmetros fisiológicos e sanitários de sementes de soja, cujas plantas foram submetidas em campo a tratamentos para o controle da ferrugem asiática, avaliando-se possíveis efeitos residuais desses tratamentos, no controle dos patógenos transmitidos pelas sementes.

\section{MATERIAL E MÉTODOS}

O ensaio em campo foi na cidade de Paulínia pertencente ao Estado de São Paulo, com: latitude de $22^{\circ} 45^{\prime} 40^{\prime \prime}$, longitude de $47^{\circ} 09^{\prime} 15^{\prime \prime}$ e altitude de $590 \mathrm{~m}$. No campo de produção de sementes, utilizou-se o cultivar de soja BRS-133, cultivado na safra 2006/2007, indicado para as condições geográficas da região.

A semeadura ocorreu na segunda quinzena no mês de outubro de 2006, em campo experimental. Utilizou-se o delineamento em blocos ao acaso, com treze tratamentos e quatro repetições, a área útil das parcelas foi de $5 \mathrm{~m}^{2}$. O preparo do solo, a adubação, a irrigação, o controle fitossanitário e de plantas invasoras foram efetuadas conforme as recomendações para a cultura da soja (EMBRAPA, 2006).

As pulverizações para o controle da ferrugem foram efetuadas aos dois e três meses após a semeadura, utilizandose um costal à base de $\mathrm{CO}_{2}$. Os tratamentos utilizados e as doses estão listados na Tabela 1 .

No mês de fevereiro de 2007, realizou-se a colheita manual das linhas centrais das parcelas, sendo que cada parcela representou um tratamento informado na Tabela 1. 
TABELA 1. Tratamentos utilizados no controle da ferrugem asiática em plantas de soja, cultivar BRS-133.

\begin{tabular}{lllc}
\hline \multicolumn{1}{c}{ Tratamento } & \multicolumn{1}{c}{ Ingrediente ativo } & $\begin{array}{c}\text { Dose } \\
\text { L p.c. ha } \text { h }^{-1}\end{array}$ \\
\hline 1 & Testemunha & azoxistrobina (Syngenta) & 0,20 \\
2 & Priori + Nimbus 0,5\% v/v & picoxistrobina (Du Pont) & 0,20 \\
3 & Aproach + Nimbus 0,5\% v/v & azoxistrobina + ciproconazole (Syngenta) & 0,30 \\
4 & Priori Xtra + Nimbus 0,5\% v/v & ciproconazole + trifloxistrobina (Bayer) & 0,30 \\
5 & Sphere + Aureo 250 mL/ha & epoxiconazole + piraclostrobina (Basf) & 0,50 \\
6 & Opera & propiconazole + trifloxistrobina (Bayer) & 0,40 \\
7 & Stratego + Aureo 250 mL/ha & tebuconazole + trifloxystrobin (Bayer) & 0,50 \\
8 & Nativo + Aureo 0,25 \%v/v & flutriafol + tiofanato metílico (Cheminova) & 0,60 \\
9 & Impact Duo + Oppa 1\% v/v & flutriafol + tiofanato metílico (Ihara) & 0,60 \\
10 & Celeiro + Iharol 1\% v/v & flutriafol + carbendazin (Cheminova) & 0,70 \\
11 & Battle + Oppa 1\% v/v & picoxistrobina + ciproconazole (Du Pont) & 0,30 \\
12 & Aproach Prima + Nimbus 0,5\% v/v ${ }^{1}$ & tebuconazole (Bayer) & 0,50 \\
13 & Folicur & & \\
\hline
\end{tabular}

Posteriormente, as sementes foram distribuídas em bandejas, formando uma camada única, e colocadas dentro de uma estufa com circulação de ar a $29^{\circ} \mathrm{C}$ até que atingissem teor de água próximo a $12,0 \%$. Depois de secas, as sementes foram embaladas em sacos de papelão identificados e acondicionadas em câmara $\left(20{ }^{\circ} \mathrm{C}\right.$ e $60 \%$ de umidade relativa do ar). Após a retirada de amostras de sementes suficientes para a realização de cada teste, as embalagens foram novamente fechadas e armazenadas.

A avaliação da qualidade das sementes foi realizada no Laboratório de Análise de Sementes do Departamento de Produção Vegetal e no Laboratório de Patologia de Sementes do Departamento de Entomologia, Fitopatologia e Zoologia Agrícola, ambos pertencentes à Universidade de São Paulo, da Escola Superior de Agricultura "Luiz de Queiroz", em Piracicaba/SP. Foram feitas as seguintes avaliações:

Teor de água: determinado pelo método de estufa (105+ $3{ }^{\circ} \mathrm{C}$, durante $24 \mathrm{~h}$ ); os resultados, expressos em porcentagem, foram calculados com base na massa úmida (Brasil, 1992).

Germinação: foram utilizadas 200 sementes por tratamento, sendo 50 sementes por subamostra, colocadas para germinar em rolo de papel (tipo germitest) umedecido com 2,5 vezes a massa do substrato. Os rolos foram colocados em germinador a $25^{\circ} \mathrm{C}$ e as avaliações foram realizadas no quinto e oitavo dias após a instalação do teste, de acordo com as Regras para Análise de Sementes (Brasil, 1992). Os resultados foram expressos em porcentagem de plântulas normais.

Envelhecimento acelerado: adotou-se metodologia descrita por Marcos Filho et al., (1987), com o uso de caixas plásticas $(11,5 \times 11,5 \times 3,5 \mathrm{~cm})$ como compartimentos individuais (mini-câmaras), possuindo em seu interior suportes para apoio de uma tela metálica, onde foram distribuídas as sementes em camada única. No interior de cada caixa foram adicionados $40 \mathrm{~mL}$ de água e as mesmas foram colocadas em câmara tipo BOD a $41{ }^{\circ} \mathrm{C}$ por $48 \mathrm{~h}$. Decorrido o período de envelhecimento, quatro subamostras de 50 sementes de cada tratamento foram colocadas para germinar, conforme o processo de germinação descrito acima e a avaliação foi realizada no quinto dia após a semeadura. Os resultados foram expressos em porcentagem de plântulas normais.

Emergência de plântulas: o teste foi conduzido com quatro repetições de 50 sementes para cada tratamento, semeadas em bandejas e distribuídas em sulcos de $20 \mathrm{~cm}$ de comprimento e $2 \mathrm{~cm}$ de profundidade, contendo como substrato a areia, umedecida $60 \%$ da capacidade máxima de retenção de água do substrato (Brasil, 1992). As bandejas foram mantidas em casa de vegetação, sendo o teste avaliado no oitavo dia após a semeadura. Os resultados foram expressos em porcentagens de plântulas normais.

Teste de sanidade: para a realização do teste, foram utilizadas 400 sementes por tratamento, sendo 100 sementes por repetição, incubadas pelo método papel filtro, que consistiu em incubar sementes em placas de Petri, sobre três folhas de papel filtro sobrepostas, umedecidas com água destilada. As sementes ficaram sete dias a $20^{\circ} \mathrm{C}$, num regime intermitente de $12 \mathrm{~h}$ de luz e $12 \mathrm{~h}$ de escuro (Brasil, 
1992). Decorrido esse período, as sementes foram analisadas sob microscópio estereoscópico e os patógenos foram identificados e quantificados.

Análise Estatística: o delineamento utilizado foi em blocos ao acaso, sendo que os resultados dos testes de germinação, envelhecimento acelerado e emergência, expressos em porcentagem, foram transformados em arco seno $\sqrt{x} / 100$ e do teste de sanidade em $\sqrt{ }(x+0,5)$. Realizou-se a análise empregando o sistema SANEST para computadores (Zonta e Machado, 1984) e as médias comparadas pelo teste de Tukey $(\mathrm{p}<0,05)$.

\section{RESULTADOS E DISCUSSÃO}

Considerando o teor de água das sementes antes e após o envelhecimento acelerado (Tabela 2), observou-se que os tratamentos apresentaram umidade inicial variando de 10,3 a $11,9 \%$ antes da condução do teste. Após o período de exposição ao envelhecimento, a umidade das sementes atingiu entre 28,2 e $30,8 \%$, estando de acordo com os valores referenciais citados por Marcos Filho (1999), destacando que a uniformização do teor de água das sementes é imprescindível para a confiabilidade das avaliações para essa faixa de umidade inicial.

TABELA 2. Resultados do teor de água antes e após o teste de envelhecimento acelerado (EA), de germinação, emergência de plântulas e envelhecimento acelerado (EA), em sementes de soja, cultivar BRS-133.

\begin{tabular}{|c|c|c|c|c|c|}
\hline \multirow{2}{*}{ Tratamentos $^{(1)}$} & \multicolumn{2}{|c|}{ Teor de água } & \multirow{2}{*}{ Germinação } & \multirow{2}{*}{ Emergência de plântulas } & \multirow{2}{*}{ EA } \\
\hline & inicial & após EA & & & \\
\hline & \multicolumn{5}{|c|}{ 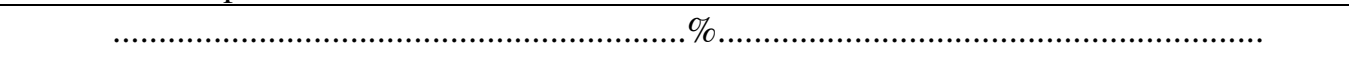 } \\
\hline 1 & 10,9 & 29,5 & $96 \mathrm{a}$ & $92 \mathrm{a}$ & $88 \mathrm{a}$ \\
\hline 2 & 11,4 & 29,3 & $98 \mathrm{a}$ & $94 \mathrm{a}$ & $93 \mathrm{a}$ \\
\hline 3 & 11,2 & 28,8 & $97 \mathrm{a}$ & $93 \mathrm{a}$ & $82 \mathrm{a}$ \\
\hline 4 & 11,8 & 28,8 & $96 \mathrm{a}$ & $93 a$ & $86 a$ \\
\hline 5 & 10,6 & 28,9 & $96 a$ & $95 \mathrm{a}$ & $89 a$ \\
\hline 6 & 11,7 & 29,9 & $96 a$ & $91 \mathrm{a}$ & $89 a$ \\
\hline 7 & 11,2 & 28,2 & $97 \mathrm{a}$ & $92 \mathrm{a}$ & $88 \mathrm{a}$ \\
\hline 8 & 11,7 & 29,8 & $98 \mathrm{a}$ & $93 a$ & $93 a$ \\
\hline 9 & 11,3 & 29,7 & $95 \mathrm{a}$ & $95 \mathrm{a}$ & $89 a$ \\
\hline 10 & 11,9 & 29,9 & $97 \mathrm{a}$ & $93 a$ & $93 a$ \\
\hline 11 & 11,5 & 30,8 & $97 \mathrm{a}$ & $93 a$ & $95 a$ \\
\hline 12 & 10,5 & 29,4 & $97 \mathrm{a}$ & $94 a$ & $88 \mathrm{a}$ \\
\hline 13 & 10,3 & 30,2 & $95 \mathrm{a}$ & $93 \mathrm{a}$ & $86 a$ \\
\hline $\mathrm{CV}(\%)$ & - & - & 5,63 & 4,4 & 6,91 \\
\hline
\end{tabular}

${ }^{(1)}$ Os tratamentos numerados estão descritos na Tabela 1.

Médias seguidas pela mesma letra, na coluna, não diferem entre si pelo teste de Tukey $(\mathrm{p}<0,05)$.

A avaliação da qualidade das sementes, pelo teste de germinação em papel, não apresentou diferenças significativas entre os tratamentos (Tabela 2), sendo que em todos os tratamentos apresentaram percentagens média de plântulas normais superiores à mínima estabelecida para a comercialização de sementes de soja, ou seja, 80 $\%$ de germinação (MAPA, 2005). Os resultados do teste de emergência de plântulas (Tabela 2) não demonstraram diferenças significativas entre os tratamentos; observa-se que a germinação das sementes obteve percentagem mínima de $91 \%$, indicativo que as condições ambientais para o teste foram adequadas para o desenvolvimento das plântulas.
No momento da avaliação do teste de germinação, observaram-se anormalidades em algumas plântulas nos tratamentos em que foram aplicados fungicidas, entretanto a ocorrência destas plântulas anormais não alterou estatisticamente os resultados no teste de germinação. Os sintomas observados se caracterizaram por engrossamento, encurtamento e rigidez do hipocótilo. Estes sintomas descritos são característicos de fitotoxidade e podem ser constatados em diferentes intensidades nas plântulas, variando entre diferentes cultivares de soja (França Neto et al., 2000).

Nos resultados do teste de sanidade para as sementes de soja (Tabela 3) não houve diferença estatística entre os 
tratamentos para os patógenos: Phomopsis sp., Fusarium sp., Aspergillus spp., Penicillium spp e Colletotrichum dematium e a testemunha, indicando que esses fungicidas utilizados no controle da ferrugem asiática não influenciaram a infecção das sementes por esses patógenos. Apesar da análise estatística não indicar diferença entre os tratamentos para o patógeno Aspergillus spp. e Penicillium spp., provavelmente devido ao alto coeficiente de variação, observa-se que houve maior incidência do fungo na testemunha e no tratamento 6 (Opera).

TABELA 3 . Resultados da avaliação do teste de sanidade em sementes de soja, cultivar BRS-133, expressos em percentagem de sementes infectadas.

\begin{tabular}{cccccrr}
\hline Tratamentos $^{(1)}$ & Phomopsis sp. & Fusarium sp. & $\begin{array}{c}\text { Cercospora } \\
\text { kikuchii }\end{array}$ & Aspegillus spp. & Penicillium spp. & $\begin{array}{c}\text { Colletotrichum } \\
\text { dematium }\end{array}$ \\
\hline 1 & $3,4 \mathrm{a}$ & $4,7 \mathrm{a}$ & $2,7 \mathrm{ab}$ & $13,3 \mathrm{a}$ & $3,6 \mathrm{a}$ & $0 \mathrm{a}$ \\
2 & $3,2 \mathrm{a}$ & $2,9 \mathrm{a}$ & $3,7 \mathrm{ab}$ & $4,2 \mathrm{a}$ & $0,2 \mathrm{a}$ & $0,2 \mathrm{a}$ \\
3 & $2,9 \mathrm{a}$ & $3,3 \mathrm{a}$ & $3,0 \mathrm{ab}$ & $8,0 \mathrm{a}$ & $0 \mathrm{a}$ & $0 \mathrm{a}$ \\
4 & $3,6 \mathrm{a}$ & $3,6 \mathrm{a}$ & $6,3 \mathrm{a}$ & $4,6 \mathrm{a}$ & $0,8 \mathrm{a}$ & $0,4 \mathrm{a}$ \\
5 & $2,4 \mathrm{a}$ & $2,0 \mathrm{a}$ & $4,4 \mathrm{ab}$ & $0,6 \mathrm{a}$ & $0,4 \mathrm{a}$ & $0 \mathrm{a}$ \\
6 & $3,9 \mathrm{a}$ & $3,1 \mathrm{a}$ & $4,5 \mathrm{ab}$ & $14,9 \mathrm{a}$ & $1,3 \mathrm{a}$ & $0 \mathrm{a}$ \\
7 & $3,2 \mathrm{a}$ & $4,5 \mathrm{a}$ & $4,6 \mathrm{ab}$ & $2,4 \mathrm{a}$ & $0,4 \mathrm{a}$ & $0 \mathrm{a}$ \\
8 & $3,4 \mathrm{a}$ & $1,7 \mathrm{a}$ & $5,5 \mathrm{ab}$ & $4,2 \mathrm{a}$ & $0 \mathrm{a}$ & $0,2 \mathrm{a}$ \\
9 & $3,3 \mathrm{a}$ & $4,2 \mathrm{a}$ & $0,9 \mathrm{ab}$ & $2,2 \mathrm{a}$ & $0 \mathrm{a}$ & $0,2 \mathrm{a}$ \\
10 & $3,1 \mathrm{a}$ & $4,9 \mathrm{a}$ & $4,9 \mathrm{ab}$ & $2,1 \mathrm{a}$ & $0,9 \mathrm{a}$ & $0 \mathrm{a}$ \\
11 & $4,7 \mathrm{a}$ & $3,2 \mathrm{a}$ & $0,4 \mathrm{~b}$ & $7,0 \mathrm{a}$ & $0,9 \mathrm{a}$ & $0 \mathrm{a}$ \\
12 & $2,6 \mathrm{a}$ & $1,7 \mathrm{a}$ & $5,9 \mathrm{a}$ & $6,2 \mathrm{a}$ & $0,2 \mathrm{a}$ & $0,2 \mathrm{a}$ \\
\hline CV $(\%)$ & $2,6 \mathrm{a}$ & $3,5 \mathrm{a}$ & $3,1 \mathrm{ab}$ & $8,5 \mathrm{a}$ & $0,9 \mathrm{a}$ & $0,2 \mathrm{a}$ \\
\hline
\end{tabular}

(1) Os tratamentos numerados estão descritos na Tabela 1.

Médias seguidas pela mesma letra, na coluna, não diferem entre si pelo teste de Tukey $(p<0,05)$.

Constatou-se a diferença nos tratamentos, quando avaliado a incidência do fungo Cercospora kikuchii. O controle mais eficiente foi quando se utilizou o tratamento 11 (Battle + Oppa), onde os princípios ativos do fungicida são flutriafol e carbendazin. O flutriafol por ser um produto sistêmico e de rápida translocação pela planta é indicado no controle da ferrugem asiática e também é utilizado no controle de Cercospora kikuchii (Cheminova, 2007).

A maior incidência da Cercospora kikuchii foi encontrada nos tratamentos 4 (Priori Xtra+Nimbus) e 12 (Aproach Prima+Nimbus). Apesar de ambos os produtos serem indicados para o controle da Cercospora kikuchii (Syngenta, 2007; Du Pont, 2007), mostraram baixa eficiência. Esses resultados podem estar relacionados com a resistência que o patógeno adquiriu em relação a estes princípios ativos, o que os torna menos eficientes no controle da doença, quando comparado aos demais tratamentos utilizados.

\section{CONCLUSÕES}

Os tratamentos utilizados para o controle da ferrugem asiática não prejudicam a qualidade das sementes.

A aplicação de Battle + Oppa (flutriafol + carbendazin) no controle de ferrugem asiática em plantas de soja diminuiu a incidência do patógeno Cercospora kikuchii nas sementes.

\section{AGRADECIMENTOS}

Ao CNPq e à FAPESP pelo financiamento da pesquisa.

\section{REFERÊNCIAS}

BRASIL. Ministério da Agricultura e Reforma Agrária. Secretaria Nacional de Defesa Agropecuária. Departamento 
Nacional de Produção Vegetal. Coordenação de Laboratório Vegetal. Regras para Análise de Sementes. Brasília, DF, 1992. $365 \mathrm{p}$.

CHEMINOVA - Disponível em: $<$ http://www.cheminova. com.br>. Acesso em: 16 jun. 2007.

CONAB. Companhia Nacional de Abastecimento. Balanço de oferta e demanda mundial. Disponível em: <www. conab.gov.br>. Acesso em: 18 fev.2009.

DU PONT - Disponível em: < http://www.dupontagricola. com.br>. Acesso em: 16 jun. 2007.

EMBRAPA. Consórcio Anti ferrugem confirma três focos de ferrugem asiática na safra 2008/09. Disponível em:<www.embrapa.br/imprensa/noticias/2008/dezembro $>$. Acesso em: 19 fev.2009.

EMBRAPA. Plantio antecipado da soja pode reduzir perda com ferrugem asiática. Disponível em: $<$ www. embrapa.br/imprensa/noticias/2002/agosto $>$.Acesso em: 19 fev.2009.

EMBRAPA. Sistema de alerta: informações sobre a ferrugem. Disponível em: $<$ www.cnpso.embrapa.br/alerta $>$. Acesso em: 15 jun. 2007.

FRANÇA NETO, J.B.; HENNING, A.A.; YORINORI, J.T. Caracterização dos problemas de fitotoxicidade de plântulas de soja devido ao tratamento de sementes com fungicida Rhodiauram 500 SC, na safra 2000/01. Londrina: Embrapa Soja, 2000. 24p. (Embrapa Soja. Circular Técnica, 27).

GODOY, C.V.; CANTERI, M.G. Efeitos protetor, curativo e erradicante de fungicidas no controle da ferrugem da soja causada por Phakopsora pachyrhizi, em casa de vegetação. Fitopatologia brasileira, v.29, n.1, 2004.

GODOY, C.V.; PIMENTA, C.B.; WRUCK, D.S.M. Eficiência de fungicidas para controle da ferrugem asiática da soja, Phakopsora pachyrhizi, na safra 2006/07. Resultados sumarizados dos ensaios em rede. Londrina: Embrapa Soja, 2007. 8p. (Embrapa Soja, Circular Técnica, 42).

GUIRALDO, N.; AMBROSANO, E.J.; MENDES, P.C.D.; ROSSI, F.; AVÉRALO, R.A. Controle de doenças em sistema agroecológicos. Summa Phytopathologica, v.30, n.1, p.153-156, 2004.

JULIATTI, F.C. Modo de ação dos fungicidas sobre plantas e fungos. Disponível em: $<$ http://ppi-ppic-ipi.org/ ppiweb/pbrazil.nsf>. Acesso em: 15 jun. 2007.

KLINGELFUSS, L.H.; YORINORI, J.T. Infecção latente de Colletotrichum truncatum e Cercospora kikuchii em soja.
Fitopatologia Brasileira, v.26, n.2, 2001.

MAPA. Ministério da Agricultura, Pecuária e Abastecimento. Disponível em: <http://extranet.agricultura.gov.br/ sislegis-consulta/consultarLegislacao.do?Operação = visualizar\&id=16534>. Acesso em: 21 set. 2009.

MARCOS FILHO, J. Teste de envelhecimento acelerado. In: KRZYZANOWSKI, F. C.; VIEIRA, R.D.; FRANÇA NETO, J.B. (Ed.). Vigor de sementes: conceitos e testes. Londrina: ABRATES,1999. cap.3, p.1-24.

MARCOS FILHO, J.; CÍCERO, S.M.; SILVA, W.R. Avaliação da qualidade das sementes. Piracicaba: FEALQ, 1987. $230 \mathrm{p}$.

SINCLAIR, J.B.; HARTMAN, G.L. Management of Soybean Rust. In: SOYBEAN RUST WORKSHOP. 1995. URBANA. Proceedings... Urbana: College of Agricultural, Consumer and Environmental Sciences, 1995. p.6-10

SOARES, R.M.; RUBIN, S.A.L.; WIELEWICKI, A.P.; OZELAME, J.G. Fungicidas no controle da ferrugem asiática (Phakopsora pachyrhizi) e produtividade da soja. Ciência Rural, v.34, n.4, 2004.

SYNGENTA - Disponível em: <http://www.syngenta.com. br>. Acesso em: 16 jun. 2007.

TECNOLOGIAS de produção de soja - região central do Brasil 2007. Londrina: Embrapa Soja: Embrapa Cerrados: Embrapa Agropecuária Oeste, 2006. 225p. (Embrapa Soja. Sistemas de Produção, 11).

VIEIRA, R.F.; PAULA JÚNIOR, T.J.; PERES, A.P.; MACHADO, J.C. Fungicidas aplicados via água de irrigação no controle do mofo-braco no feijoeiro e incidência do patógeno na semente. Fitopatologia Brasileira, v.26, n.4, 2001.

YORINORI, J.T. Situação atual das doenças potenciais no Cone Sul. In: CONGRESSO BRASILEIRO DE SOJA E MERCOSOJA, 2., 2002, Foz do Iguaçu. Anais... Londrina: Embrapa Soja, 2002. p. 171-186. (Embrapa Soja. Documentos, 180).

YORINORI, J.T., PAIVA, W.M., FREDERICK, R.D.; FERNANDEZ, P.F.T. Ferrugem da soja (Phakopsora pachyrhizi) no Brasil e no Paraguai, nas safras 2000/01. In: CONGRESSO BRASILEIRO DE SOJA, 2., MERCOSOJA 2002, Foz do Iguaçu. Resumos... Londrina: Embrapa Soja, 2002. p.94. (Embrapa Soja. Documentos, 181).

ZONTA, E.P.; MACHADO, A.A. Sistema de Análise Estatística para Microcomputadores - SANEST. Pelotas: UFPel, Instituto de Física e Matemática, 1984. 75p. 